\title{
Supplementary Data: Dynamics of Reactive Metal Adsorption on Organic Thin Films
}

Gabriella Nagy, Amy V. Walker ${ }^{*}$ 


\section{Mass Spectra of Vapor-Deposited Calcium on $-\mathrm{CH}_{3},-\mathrm{OH},-\mathrm{OCH}_{3},-\mathrm{COOH}$ and $-\mathrm{CO}_{2} \mathrm{CH}_{3}$}

\section{Terminated SAMs}

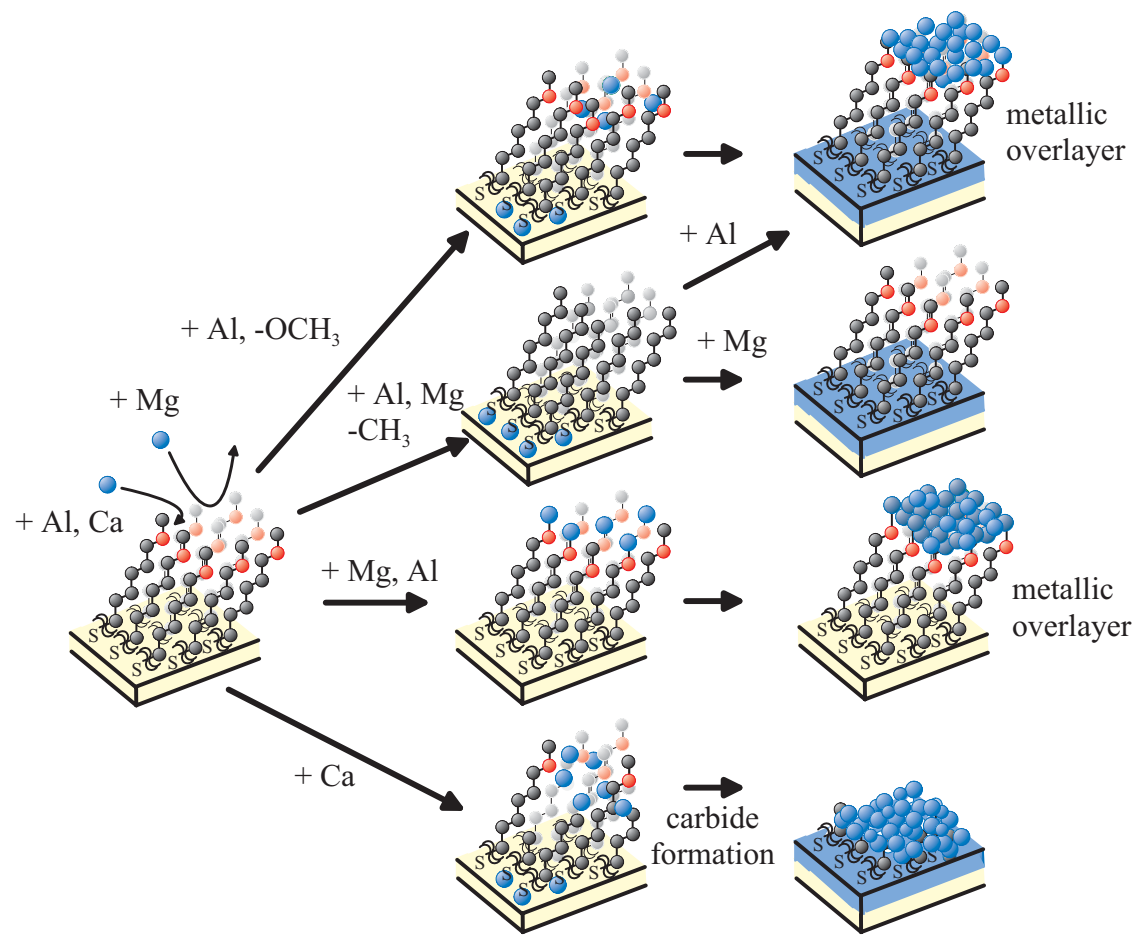

Figure 1: Schematic illustrations of the important features of the reaction pathways observed for Ca, $\mathrm{Mg}$ and $\mathrm{Al}$ deposition on $-\mathrm{CH}_{3},-\mathrm{OCH}_{3},-\mathrm{OH},-\mathrm{COOH}$ and $-\mathrm{CO}_{2} \mathrm{CH}_{3}$ terminated SAMs. The metal atoms are represented in blue, gold in yellow, oxygen in red and hydrocarbons in black. Vapor-deposited Ca reacts vigorously with these SAMs forming calcium carbide and other inorganic products (bottom row). Vapor-deposited Al both penetrates through and forms a metallic overlayer at higher coverages on $-\mathrm{CH}_{3}$ and $-\mathrm{OCH}_{3}$ terminated SAMs (top two rows). Mg penetrates through $-\mathrm{CH}_{3}$ terminated SAMs at all coverages studied (second row). Both $\mathrm{Mg}$ and $\mathrm{Al}$ react with $-\mathrm{OH},-\mathrm{COOH}$ and $-\mathrm{CO}_{2} \mathrm{CH}_{3}$ terminal groups and form a metallic overlayer at higher coverages. 
Figure 2: Positive ion mass spectra, mass range: $\mathrm{m} / \mathrm{z}=2$ to 500 , for $-\mathrm{CH}_{3},-\mathrm{OH},-\mathrm{OCH}_{3}$, $\mathrm{COOH}$ and $-\mathrm{CO}_{2} \mathrm{CH}_{3}$ terminated SAMs for the bare SAM and upon deposition of $\theta_{\mathrm{Ca}}=25.2$. 

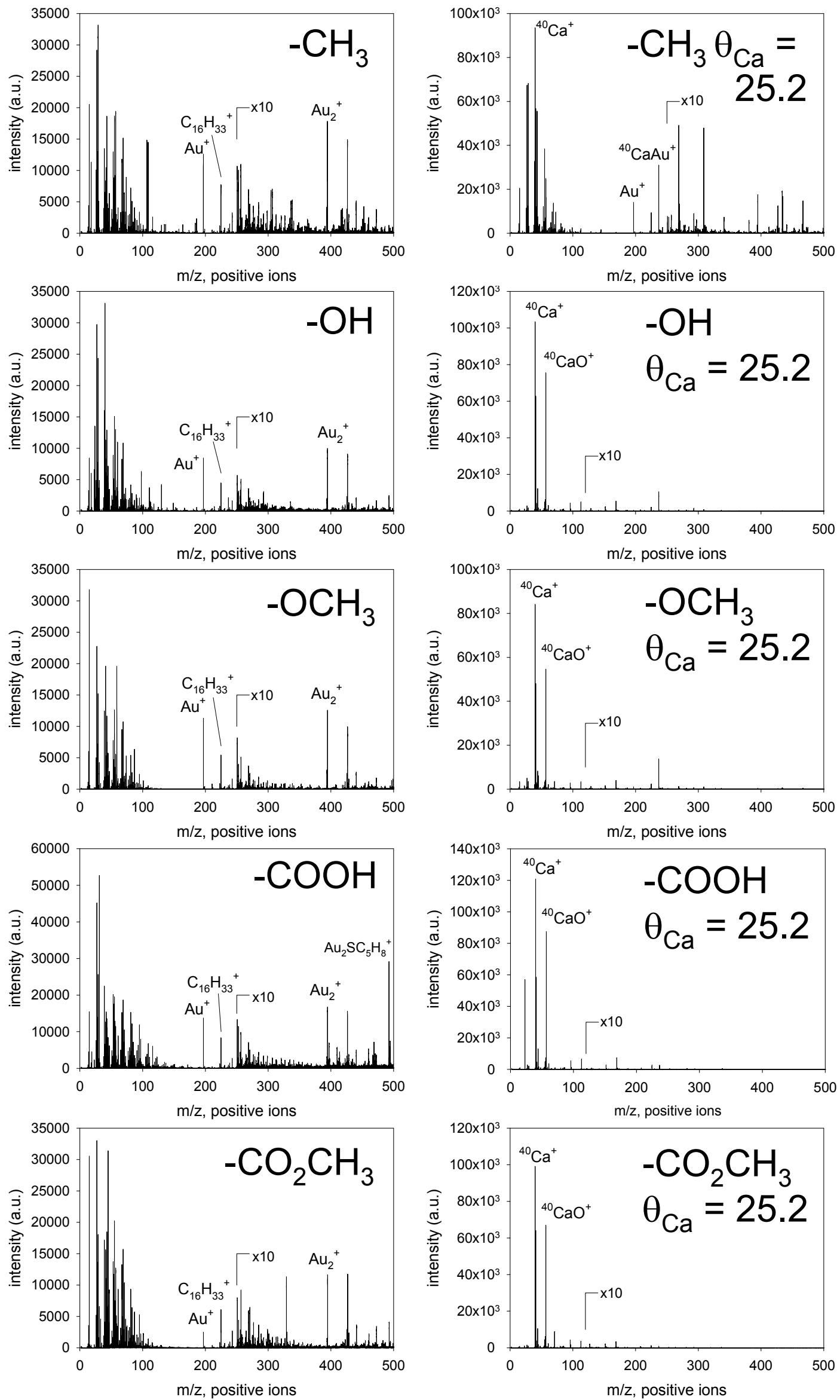
Figure 3: Negative ion mass spectra, mass range: $\mathrm{m} / \mathrm{z}=2$ to 500 , for $-\mathrm{CH}_{3},-\mathrm{OH},-\mathrm{OCH}_{3}$, $\mathrm{COOH}$ and $-\mathrm{CO}_{2} \mathrm{CH}_{3}$ terminated SAMs for the bare SAM and upon deposition of $\theta_{\mathrm{Ca}}=25.2$. 

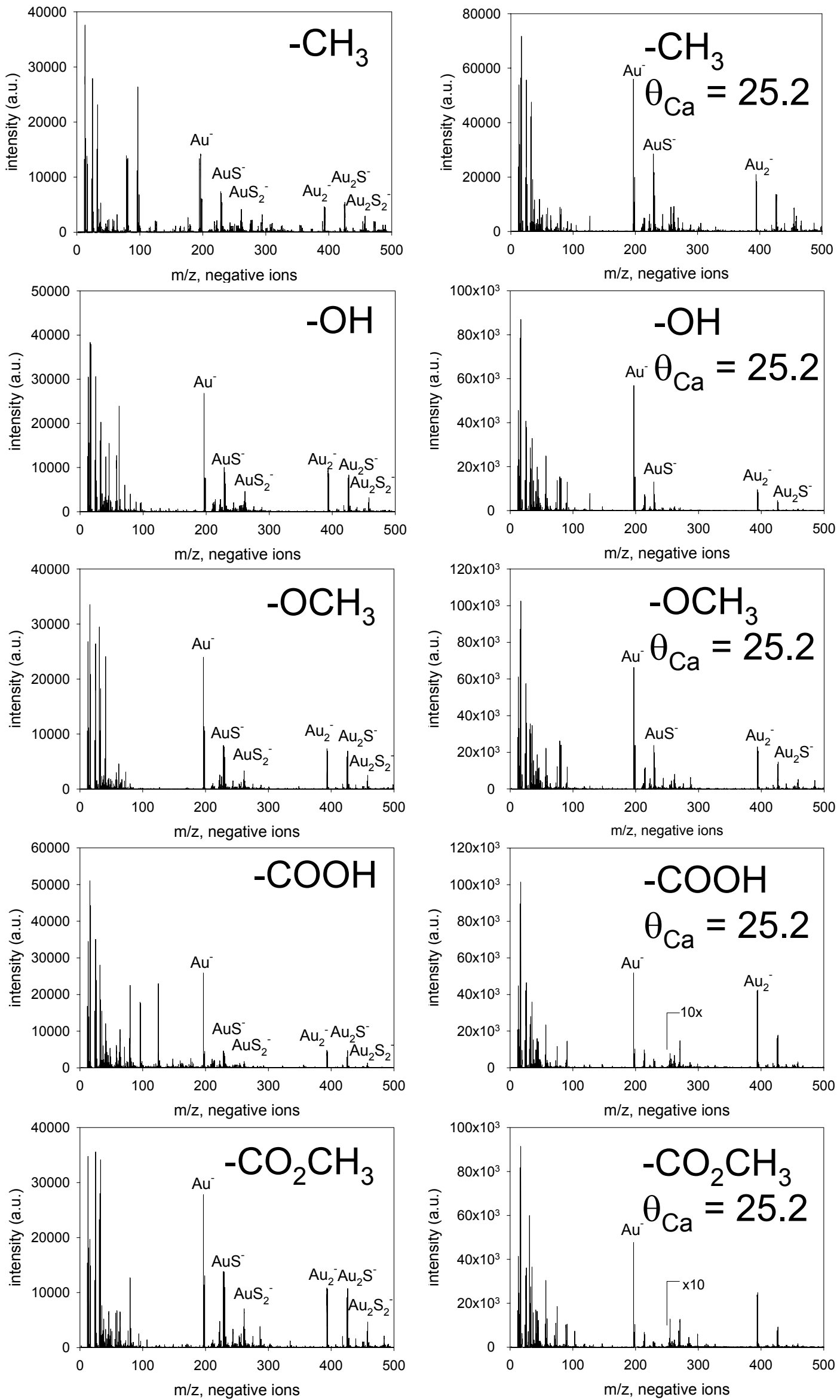
Upon deposition of Ca, for all the SAMs studied the mass spectra indicate that there is severe degradation of the SAM structure. Ions indicative of the SAM degradation include the formation of $\mathrm{CaC}^{+}, \mathrm{CaC}_{2}^{+}$(indicative of the formation of calcium carbide) and $\mathrm{AuCa}^{+}$ions (indicating that Ca is interacting with a bare gold surface). At $\theta_{\mathrm{Ca}}=25.2$ for $-\mathrm{OH},-\mathrm{OCH}_{3},-\mathrm{COOH}$ and $\mathrm{CO}_{2} \mathrm{CH}_{3}$ terminated SAMs, we observe in the positive ion mass spectra $\mathrm{Ca}^{+}$and $\mathrm{CaO}^{+}$indicating that the SAM is covered by a Ca and calcium oxide overlayer. In the negative ion spectra, we observe reduced $\mathrm{Au}_{\mathrm{n}} \mathrm{S}_{\mathrm{y}}^{-}$ions suggesting that $\mathrm{Ca}$ has reacted with the monolayer. We also observe ions of the form $\mathrm{Au}_{x} \mathrm{Ca}_{y} \mathrm{~S}_{z}^{-}$indicating that $\mathrm{Ca}$ has penetrated through the monolayers. 
Figure 4: Positive ion mass spectra, mass range: $\mathrm{m} / \mathrm{z}=2$ to 500 , for $-\mathrm{CH}_{3},-\mathrm{OH},-\mathrm{OCH}_{3}$, $\mathrm{COOH}$ and $-\mathrm{CO}_{2} \mathrm{CH}_{3}$ terminated SAMs for the bare SAM and upon deposition of $\theta_{\mathrm{Mg}}=234.9$. 

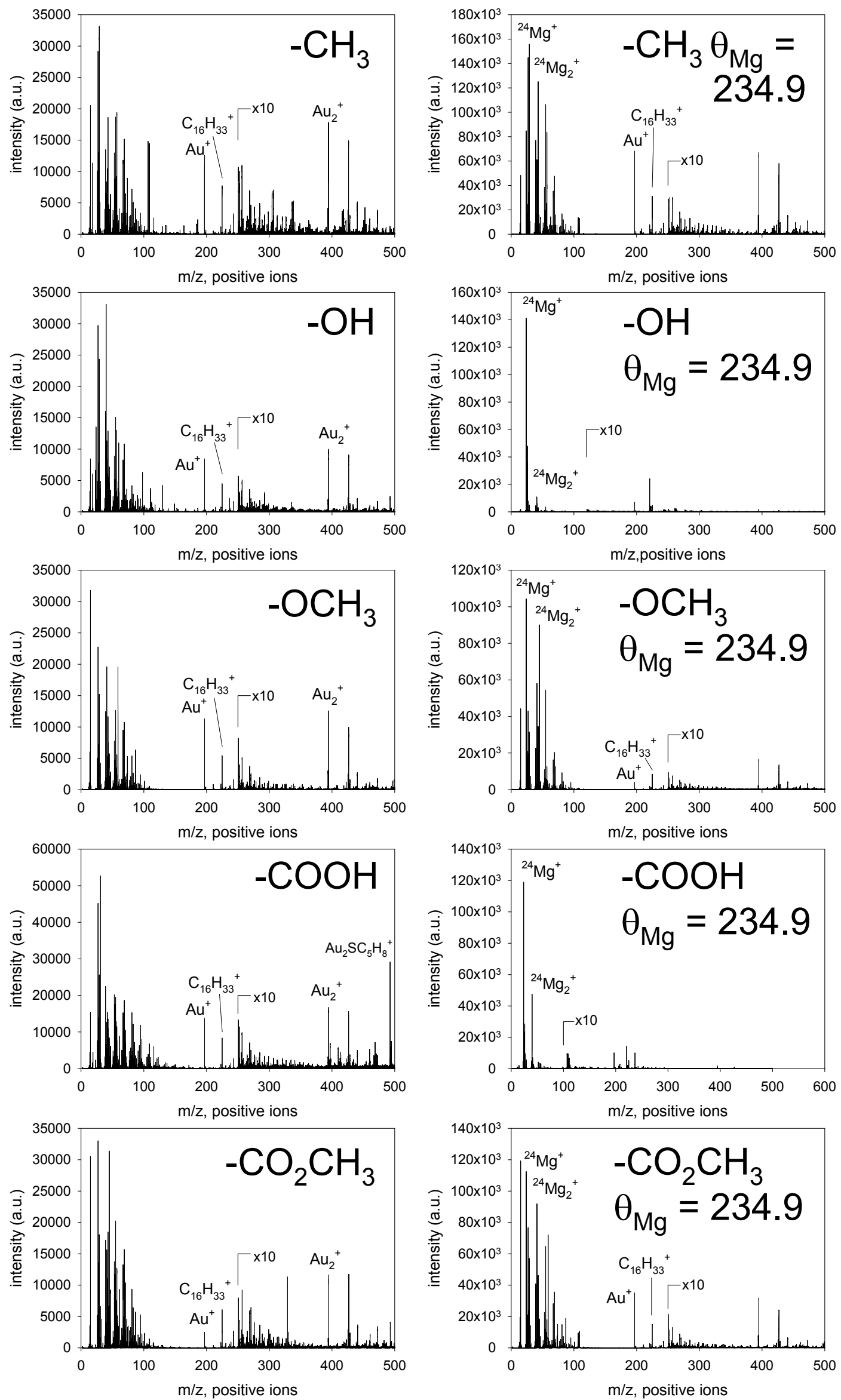
Figure 5: Negative ion mass spectra, mass range: $\mathrm{m} / \mathrm{z}=2$ to 500 , for $-\mathrm{CH}_{3},-\mathrm{OH},-\mathrm{OCH}_{3}$, $\mathrm{COOH}$ and $-\mathrm{CO}_{2} \mathrm{CH}_{3}$ terminated SAMs for the bare SAM and upon deposition of $\theta_{\mathrm{Mg}}=234.9$. 

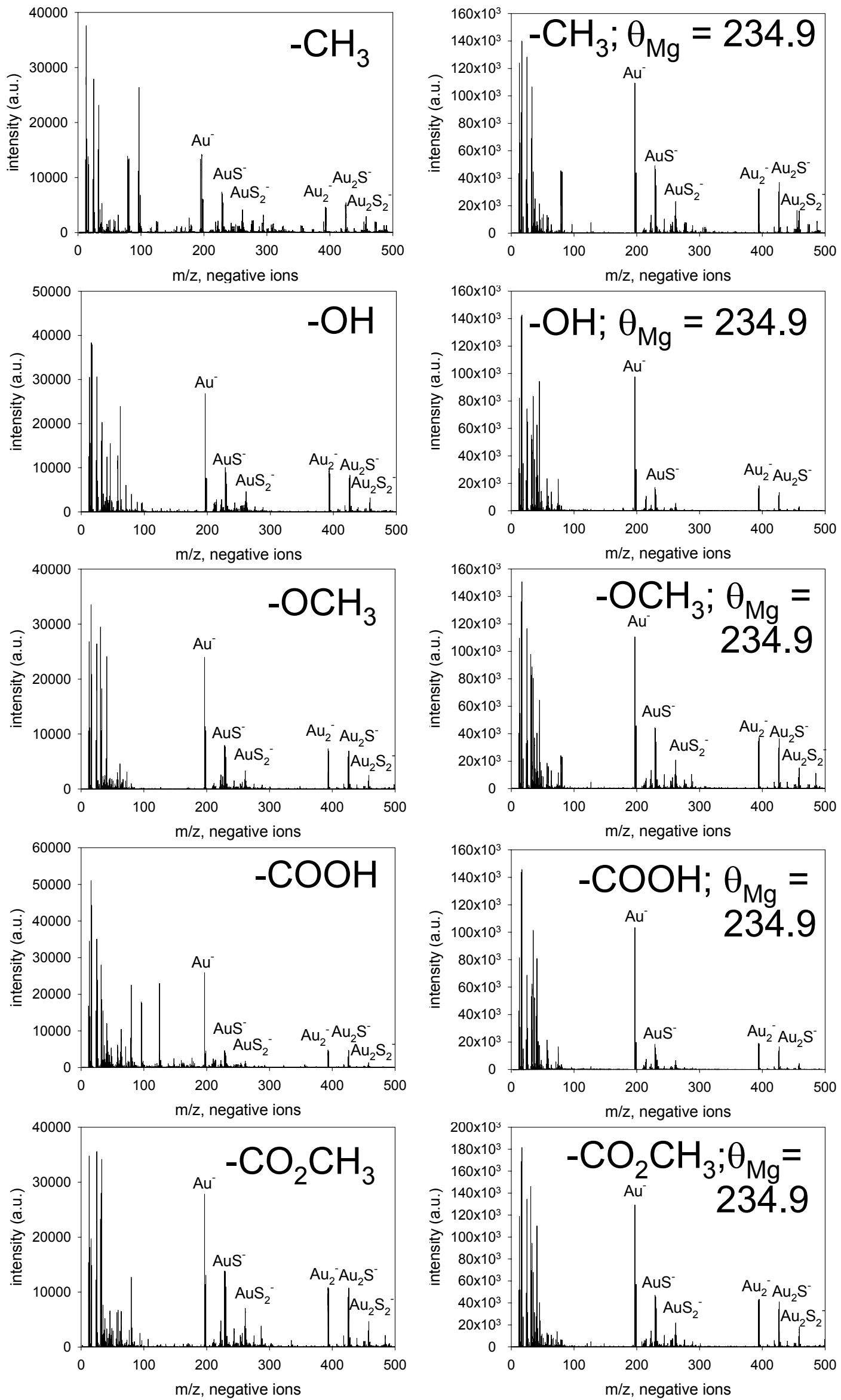
Upon deposition of $\theta_{\mathrm{Mg}}=234.9$, for $-\mathrm{CH}_{3},-\mathrm{OCH}_{3}$ and $-\mathrm{CO}_{2} \mathrm{CH}_{3}$ SAMs we observe ions indicative of the SAM indicating that deposited Mg has not formed an overlayer at the $\mathrm{SAM} /$ vacuum interface. For $-\mathrm{OH}$ and $-\mathrm{COOH}$ terminated SAMs, we observe high intensities $\mathrm{Mg}_{\mathrm{x}}{ }^{+}$ions with much reduced intensities for the ions indicative of the bare SAM. This suggests that a metallic overlayer has started to form on these surfaces. In the negative ion spectra, for all SAMs we observe high intensities of $\mathrm{Au}_{\mathrm{x}} \mathrm{S}_{\mathrm{y}}{ }^{-}$ions indicating that the $\mathrm{Mg}$ has not completely covered the underlying SAM in agreement with the positive ion mass spectra. Further for $-\mathrm{CH}_{3}$ terminated SAMs, we observe the formation of $\mathrm{Au}_{\mathrm{x}} \mathrm{Mg}_{\mathrm{y}} \mathrm{S}_{z}{ }^{-}$ions indicating that vapor deposited Mg has penetrated through the monolayer to the Au/S interface.

Figure 6 displays the intensity of the $\mathrm{Mg}_{\mathrm{x}}{ }^{+}$ions $(\mathrm{x}=1-3)$ plotted versus $\mathrm{Mg}$ dose. For $-\mathrm{CH}_{3}$ terminated SAMs, the $\mathrm{Mg}^{+}$and $\mathrm{Mg}_{2}{ }^{+}$ion intensities increase rapidly while there is a slight delay in the growth of the $\mathrm{Mg}_{3}{ }^{+}$ion intensity indicating that vapor-deposited $\mathrm{Mg}$ has penetrated through the SAM to the $\mathrm{Au} / \mathrm{S}$ interface. For $-\mathrm{OH},-\mathrm{COOH},-\mathrm{CO}_{2} \mathrm{CH}_{3}$ and $-\mathrm{OCH}_{3}$ terminated SAMs the $\mathrm{Mg}_{\mathrm{x}}{ }^{+}$ion intensities increase proportionately upon the first increments of $\mathrm{Mg}$ deposition, indicating that $\mathrm{Mg}$ reacts with the terminal group.

Figure 7 displays high resolution of mass spectra in the range $\mathrm{m} / \mathrm{z}=55.8-57.2$ for a $-\mathrm{CH}_{3}$ terminated SAM upon deposition of Mg. In the figure it can clearly be seen that no (or little) ${ }^{24} \mathrm{MgO}_{2}{ }^{-}$ion intensity is observed indicating that little or no oxygen is adsorbed from the background on the $\mathrm{Mg} / \mathrm{SAM}$ constructs. 

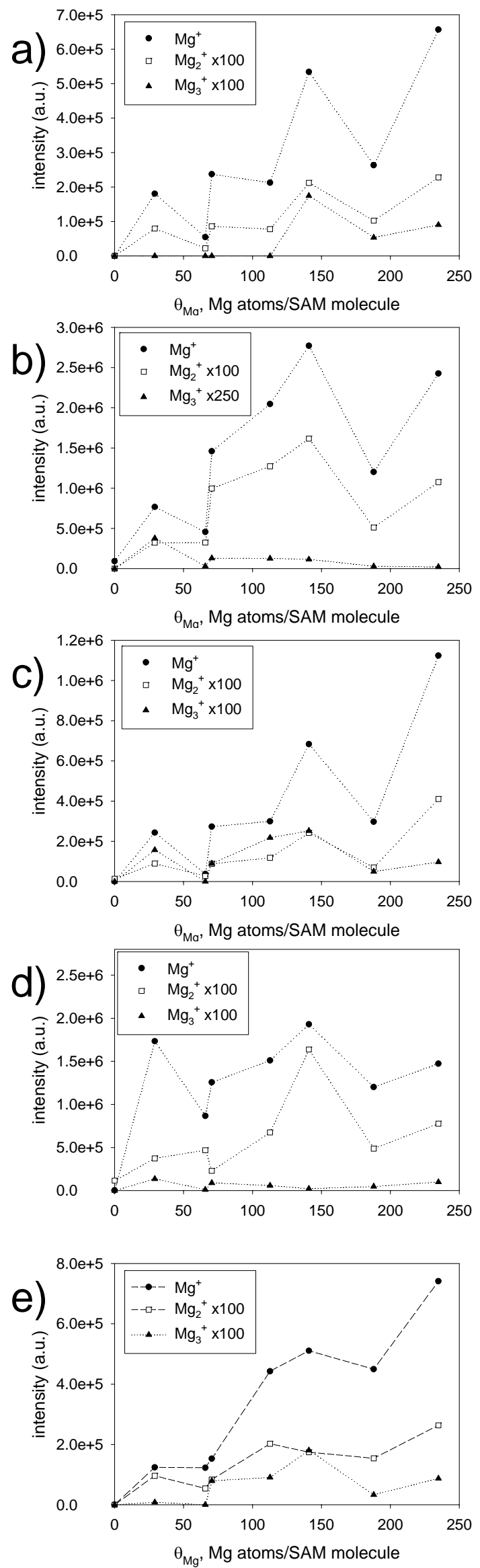

Figure 6: Integrated SIMS ion peak intensities of ${ }^{24} \mathrm{Mg}^{+},{ }^{24} \mathrm{Mg}_{2}{ }^{+}$and ${ }^{24} \mathrm{Mg}_{3}{ }^{+}$plotted versus magnesium dose for (a) $-\mathrm{CH}_{3}$, (b) $-\mathrm{OH}$, (c) $-\mathrm{OCH}_{3}$, (d) $-\mathrm{COOH}$ and (e) $-\mathrm{CO}_{2} \mathrm{CH}_{3}$ terminated SAMs. 


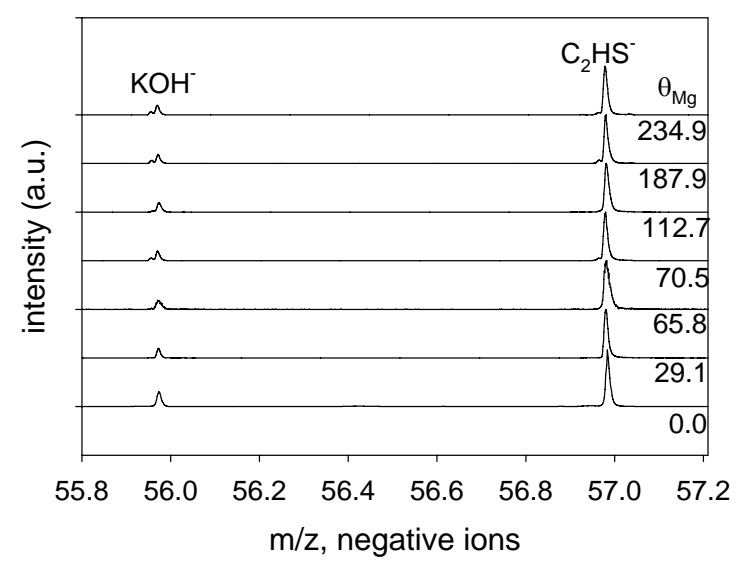

Figure 7: High resolution mass spectra of $\mathrm{m} / \mathrm{z}=55.8-57.2$ for $-\mathrm{CH}_{3}$ terminated SAMs upon deposition of Mg. The mass spectra have been normalized to the intensity of the $\mathrm{C}_{2} \mathrm{HS}^{-}$ion. 